\title{
The clinical significance of remnant thyroid tissue in thyroidectomized differentiated thyroid cancer patients on ${ }^{131} \mathrm{I}$-SPECT/CT
}

Feng Wang ${ }^{1}$, Hui Nie${ }^{2}$, Wei $\mathrm{Li}^{1 *}$, Rusen Zhang ${ }^{1}$ and Wen Li ${ }^{1}$

\begin{abstract}
Background: To explore the ${ }^{131}$ I-SPECT/CT characteristics of remnant thyroid tissue (RTT) in differentiated thyroid cancer (DTC), further assess the risk factors and clinical significance.

Methods: 52 DTC patients after total thyroidectomy had undergone neck ${ }^{131} \mathrm{I}$-SPECT/CT before ${ }^{131} \mathrm{I}$ ablation. The diagnosis of RTT was based on SPECT/CT and follow-up at least 3 months. The anatomic locations and features of SPECT/CT of RTT were assessed by reviewers. The risk factors of RTT with CT positive were analyzed by the chi-square test.

Results: A total of 80 lesions of RTT were diagnosed in this study, most of them were mainly located in the regions adjacent to trachea cartilage (37/80) or lamina of thyroid cartilage (17/80). On SPECT/CT of RTT, low, moderate and high uptake were respectively noted in 10,24 and 46 lesions, definite positive, suspected positive and negative CT findings were respectively noted in 10,21 and 49. The RTT lesions with definite positive CT findings were mainly located adjacent to lamina of thyroid cartilage $(5 / 10)$. Primary thyroid tumor $(P=0.029)$ and $T$ stage $(P=0.000)$ were the effective risk factors of CT positive RTT.

Conclusions: RTT has certain characteristic distribution and appearances on SPECT/CT. Most of RTT with definite CT abnormalities located adjacent to lamina of thyroid cartilage, which suggest surgeons should strengthen the careful removal in this region, especially primary thyroid tumor involving bilateral and T4 stage. This study can provide a certain value for the improvement of thyroidectomy quality in DTC patients.
\end{abstract}

Keywords: lodine-131, SPECT/CT, Differentiated thyroid cancer, Postoperative remnant, Thyroidectomy, Trachea cartilage, Thyroid cartilage

\section{Background}

Differentiated thyroid cancer (DTC) is one of the most common endocrine malignant tumor, including papillary thyroid carcinoma (PTC) and follicular thyroid carcinoma (FTC), which has the gradual increase rates of incidence and death in recent years [1-3]. Total

*Correspondence: liwei9741@126.com

${ }^{1}$ Department of Nuclear Medicine, Affiliated Cancer Hospital \& Institute of Guangzhou Medical University, Guangzhou 510095, Guangdong Province, China

Full list of author information is available at the end of the article thyroidectomy, radioactive iodine-131 $\left({ }^{131} \mathrm{I}\right)$ ablation, and thyroid stimulating hormone(TSH) suppression are well established treatments for DTC [4]. Complete surgical resection will be beneficial to decrease the risk of recurrence and mortality, and improve the prognosis of DTC patients [5].

However, due to the complex anatomy around thyroid, the surgical operation can easily cause the injury to important tissues such as recurrent laryngeal nerve (RLN) and parathyroid gland, which may lead to serious complications. In order to avoiding these complications, 
it is generally difficult for thyroidectomy to avoid the occurrence of remnant thyroid tissue (RTT), even for very skilled surgeons. RTT can cause the recurrence or metastasis of DTC, and badly influence the clinical prognosis [6]. Therefore, in order to maximize the benefits of patients, it is still the responsibility of every surgeon to carefully remove the thyroid tissue to minimize RTT. But, the effect of reducing RTT and improving the quality of surgery has been very little in recent years. It may be associated with the fact that the distribution characteristics and risk factors of RTT have not been systematically summarized, which makes careful surgical clearance lack of a clear guidance.

RTT should be routinely detected and evaluated after thyroid surgery, which can be used to guide the individualized treatment of ${ }^{131} \mathrm{I}$ ablation in the next step. The comparison of diagnostic value of various methods for the detection of RTT can be seen in a large number of previous studies [7-10]. ${ }^{131}$ I-SPECT/CT (single photon emission computed tomography/ computed tomography) is recognized to be highly sensitive and specific, which has been widely used in clinical evaluation practice. However, the ${ }^{131}$ I-SPECT/CT features of RTT have not been reported in detail. Especially, when the RTT lesions were revealed the definite $\mathrm{CT}$ abnormalities on ${ }^{131} \mathrm{I}$-SPECT/ $\mathrm{CT}$, its clinical significance for surgeons remains to be further analyzed and researched.

Therefore, this study is aimed to explore the distribution and imaging characteristics of RTT in patients with DTC on ${ }^{131}$ I-SPECT/CT, to further analyze the risk factors, and to discuss its values for surgeons.

\section{Materials and methods}

\section{Ethics statement}

The present study was approved by the ethics committees of affiliated Cancer Hospital \& Institute of Guangzhou Medical University. All patients provided written informed consent for their clinical information to be reviewed by us. And all methods were carried out in accordance with the approved guidelines.

\section{Patients}

\section{Inclusion criteria}

Patients were included in this study if they (1) had a diagnosis and pathological confirmation of DTC at the affiliated Cancer hospital \& Institute Guangzhou medical university between January 2020 and July 2020, (2) have been performed total thyroidectomy and cervical lymph node dissection, (3) have clear TNM staging according to the thyroid cancer staging criteria of AJCC (American Joint Committee on Cancer) 8th edition, (4) received the first radioiodine ${ }^{131}$ I therapy within $1-3$ months after surgery, (5) have been performed ${ }^{131}$ I-WBS (whole body scan) and neck ${ }^{131}$ I-SPECT/CT within 1 week before radioiodine therapy.

\section{Exclusion criteria}

Patients were excluded from this study if they (1) underwent subtotal thyroidectomy, (2) lacked of information about the primary tumor, (3) had a synchronous malignant tumor of other site, (4) had not be followed up for more than 3 months.

Finally, a total of 52 patients with DTC were included in this study, 25 females and 27 males, aged range 11-67 years, median age 40 years. Among them, pathology confirmed the diagnosis of PTC in 50 cases and FTC in 2 cases.

\section{Surgery}

All patients had received the surgical operations of total thyroidectomy and cervical lymph node dissection. There were three kinds of operation modes, mode 1 of "complete thyroidectomy + unilateral central neck lymph node dissection", mode 2 of "complete thyroidectomy + bilateral central neck lymph node dissection" and mode 3 of "standard or modified radical operation". All patients were determined the TNM staging according to the ACJJ 8th edition after surgery.

\section{WBS and SPECT/CT acquisition}

All patients underwent scintigraphy scanning (WBS and SPECT/CT) within 3 months after surgery, using a SPECT/CT scanner (Discovery NM/CT 670 Pro, GE medical systems, Israel) with dual-headed gamma camera system, high-energy collimators and a 16-slice spiral scanning diagnostic CT. The WBS images were acquired $24-48 \mathrm{~h}$ after taking orally ${ }^{131} \mathrm{I}$ (Atomic HighTech Co. Ltd., Guangzhou, China) of 111-185 MBq, using a high-energy general purpose parallel holes collimator with $364 \mathrm{keV}$ photopeak and $256 \times 1024$ matrix. Neck hybrid SPECT/CT scanning were routinely performed after WBS acquisition. CT scan was firstly performed and the acquisition parameters were as follows:

Table 1 The regional definition of RTT

\begin{tabular}{ll}
\hline Region & Definition \\
\hline II & Adjacent to the tracheal cartilage \\
III & Adjacent to the cricoid cartilage \\
IV & Adjacent to the posterior border of thyroid cartilage \\
V & Adjacent to the thyroid lamina \\
VI & Adjacent to the midline of anterior thyroid cartilage \\
\hline
\end{tabular}


(See figure on next page.)

Fig. 1 The regions (I-VI) of RTT. In cases of a-f, the RTT lesions with high-uptake tracer activity were located respectively in region I (adjacent to the left side of tracheal cartilage), region II (adjacent to the left side of cricoid cartilage), region III (adjacent to the right posterior border of thyroid cartilage), region IV (adjacent to the left thyroid lamina), region V (adjacent to the midline of anterior thyroid cartilage) and region VI (outside the left infrahyoid muscle)

tube voltage $140 \mathrm{kV}$, tube current $200 \mathrm{~mA}$ and matrices $512 \times 512$. After CT acquisition, the SPECT acquisition protocol was started, and the parameters were as follows: $128 \times 128$ matrix, $20 \%$ energy windows at $364 \mathrm{keV}$, $60^{\circ}$ angular steps with a range of $180^{\circ}$ per gamma camera head. JET stream workstation (Philips Medical Systems) was applied to obtain the fusion images of SPECT/CT.

\section{Image interpretation}

The radionuclide images (WBS and SPECT/CT) were independently evaluated by 2 experienced nuclear medicine physicians with interpretation in consensus, using diagnostic software (Compass viewer H 4.0, Medivoly Technology Co. Ltd., Shanghai, China).

\section{Diagnosis of RTT}

Reviewers were required to determine if there was abnormal ${ }^{131}$ I uptake foci on neck. The neck foci would be routinely diagnosed as RTT, if they were located in and near the thyroid bed, ruled out the diagnosis of metastatic lymph nodes, excluded the possibility of common ectopic thyroid areas such as thyroglossal duct and root of tongue, and observed the significant decrease of ${ }^{131} \mathrm{I}$ radioactive concentration in the follow-up $[11,12]$.

\section{Locations of RTT}

The anatomic locations of RTT on neck SPECT/CT were recorded in detail. According to the distribution characteristics, the locations of RTT were divided into 6 regions (I-VI). The detailed definitions and example images of regions were shown in Table 1 and Fig. 1.

\section{SPECT/CT findings of RTT}

The features of SPECT/CT of RTT were assessed by reviewers. According the CT findings, the lesions of RTT were divided into three types, type I of definite positive findings (obvious soft tissue nodule), type II of suspected positive findings (blurry patchy shadow or soft tissue thickening), and type III of negative findings (no thicken soft tissue shadow and abnormal density). The tracer uptake level of RTT on SPECT were split into low-, moderate-, and high- uptake based on whether to be lower than, equal to or higher than those of the stomach.

\section{The clinical data of patients}

The patients with RTT of the positive CT findings (type I or/ and II) were assigned to positive group, otherwise to negative group. According to the extent of invasion, the primary thyroid tumor can be divided into unilateral (one lobe and/ or isthmus) and bilateral (double lobes). In addition, all patients were collected data as follows: age $(<55$ and $\geq 55$ ) and gender (male and female), $\mathrm{T}$ stage (T1, T2 and T3-4), N stage (N0 and N1), M stage (M0 and M1), and pathology (PTC and FTC).

\section{Statistical analysis}

The incidence rate of RTT after total thyroidectomy was calculated in DTC patients. The clinical data and imaging features of RTT were counted in detail. Categorical data are expressed as numbers and frequency (\%). The chi-square test was used to analyze the effective risk factors of RTT with positive $\mathrm{CT}$ findings.

All data was analyzed by SPSS 23.0 for windows (SPSS Inc., Chicago, IL, USA) software. $P$ value $<0.05$ were considered statistically significant.

\section{Results}

\section{All patients}

A total of 52 patients with DTC were included in this study, which were demonstrated 84 abnormal uptake foci on neck by ${ }^{131}$ I-WBS. SPECT/CT revealed a total of 106 foci on neck, among which $75.5 \%(80 / 106)$ were diagnosed as RTT, $20.8 \%(22 / 106)$ as thyroglossal tract and $3.8 \%(4 / 106)$ as metastatic lymph node. According to the CT findings, these 80 lesions of RTT were classified to type I of 10 (Fig. 2), type II of 21(Fig. 3) and type II of 49. Finally, 47 patients were confirmed the presence of RTT. The incidence rate of RTT was $90.4 \%(47 / 52)$.

\section{Location and SPECT/CT features of RTT}

The detail locations and SPECT/CT findings of these 80 RTT lesions were shown in Table 2. Of these, most lesions were found with the features: region I $(46.3 \%, 37 / 80)$ and region IV (21.3\%, 17/30), high-uptake (57.5\%. 46/80,) and moderate-uptake $(30.0 \%, 24 / 80)$ and type III $(61.3 \%, 49 / 80)$ and type II $(26.3 \%, 21 / 80)$. 


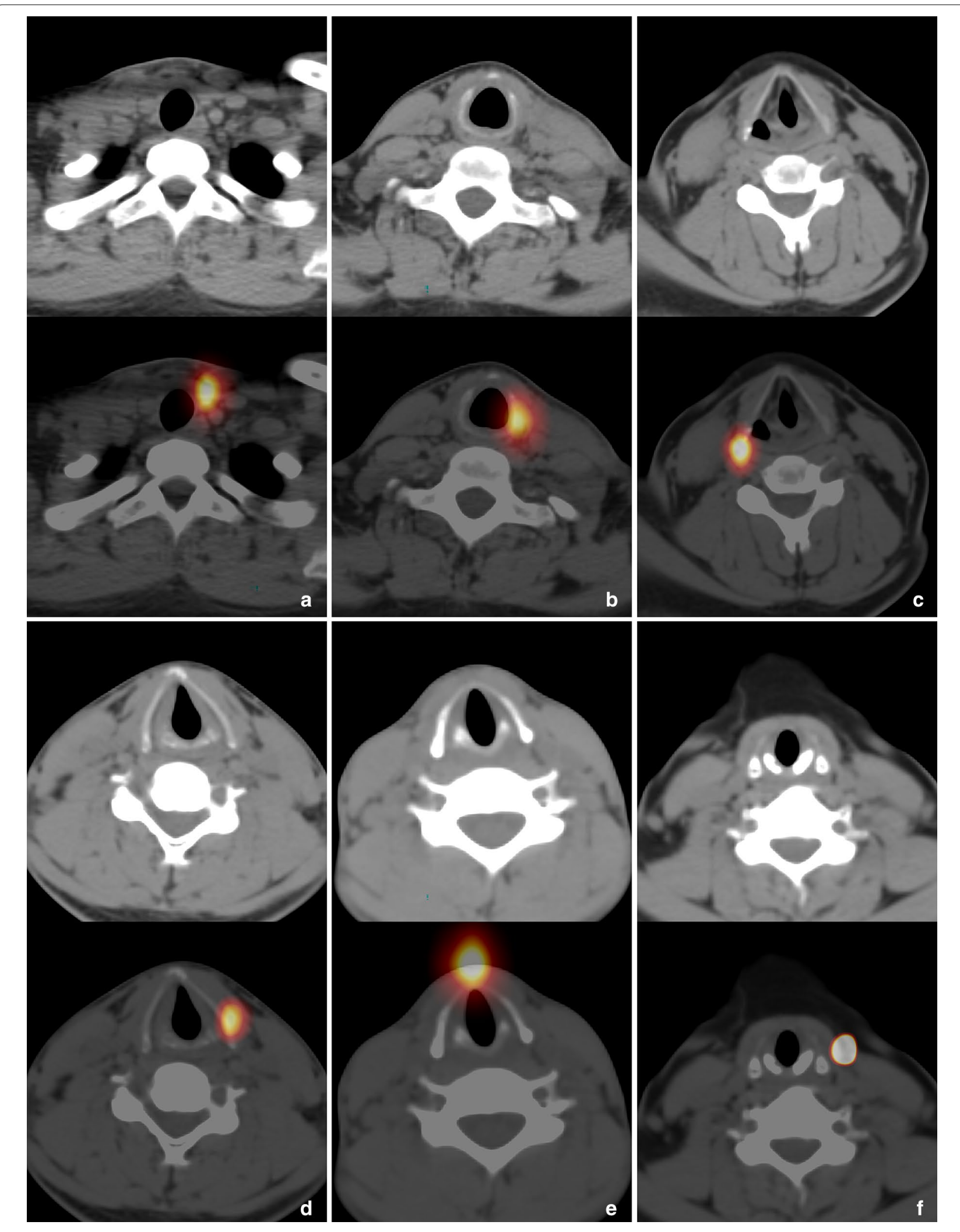



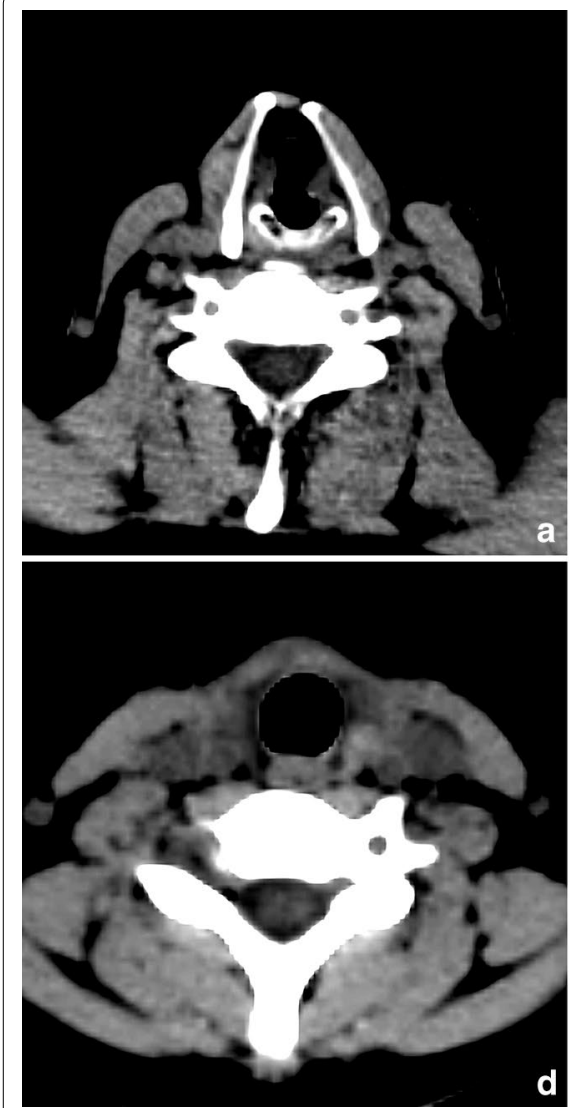
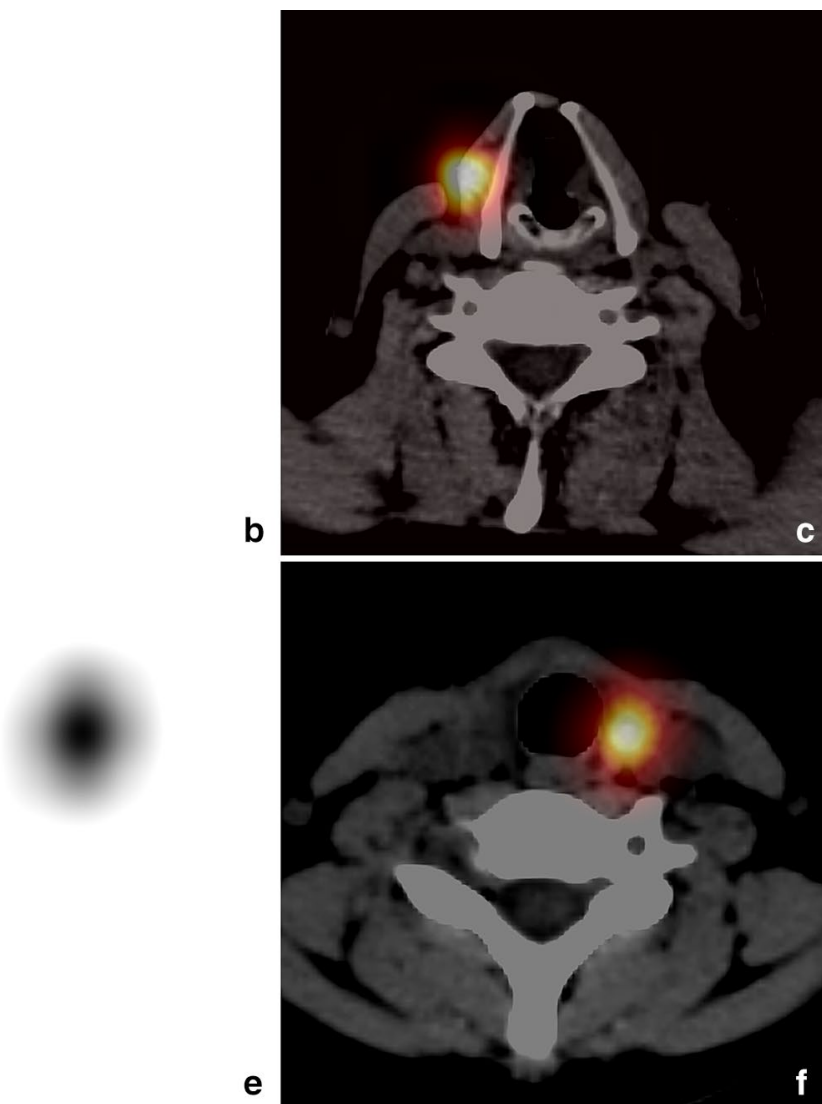

Fig. 2 RTT lesions of type I (definite positive CT findings). The images (a CT; b SPECT; c fusion) were obtained from a 42-year-old man with PTC, who underwent total thyroidectomy 2 months ago. SPECT/CT demonstrated a RTT lesion with high-uptake and soft tissue nodule, adjacent to the thyroid right lamina (region IV). The images (d CT; e SPECT; f fusion) were obtained from a 15-year-old woman with FTC, who underwent total thyroidectomy 2 months ago. SPECT/CT revealed a RTT lesion high-uptake and soft tissue nodule, adjacent to the left side of tracheal cartilage (region I)

\section{The clinical data of patients with RTT}

Based on the CT findings, 47 patients with RTT lesions were classified into positive group 29 (61.7\%) and negative group 18 (38.3\%). The correlation between various clinical data and groups was detailed shown in Table 3. By chisquare test, the data of primary thyroid tumor $(P=0.029)$ and $\mathrm{T}$ stage $(P=0.000)$ had the significant impact on the CT findings. However, other data (Age, Gender, N stage, $M$ stage, Operation mode and Pathology) was not the effective risk factors.

\section{Discussion}

Total thyroidectomy is the first choice for the treatment of DTC, but RTT is usually existed in post-thyroidectomy patients. The results of this study indicated that the incidence rate of RTT was as high as 90.4\%(47/52). Radioactive ${ }^{131} \mathrm{I}$ therapy is routinely recommended in DTC patients after total thyroidectomy, to ablate postoperative RTT and treat microscopic residual tumor foci [11-13]. The dose of ${ }^{131}$ I ablation is closely related to the number and distribution of RTT. Accurate estimation of RTT before radioiodine therapy is essential to promote the individualized treatment [14]. In addition, RTT can also increase the risk of recurrence or metastasis of DTC, which may reduce the survival of patients. Therefore, in order to improve the comprehensive prognosis of DTC patients, it is very important to precisely detect RTT and minimize RTT.

At present, the alternative image evaluation methods for RTT include CT, ultrasound, techetium-99 m pertechnetate $\left({ }^{99 \mathrm{~m}} \mathrm{TcO}_{4}{ }^{-}\right)$planar scintigraphy, ${ }^{131} \mathrm{I}-\mathrm{WBS}$ (whole-body scan) and ${ }^{131} \mathrm{I}$-SPECT/CT. Ultrasound is a convenient method, which can clearly measure the shape and size of RTT. Lee SJ [15] reported that ultrasound was not as accurate as CT in assessing the volume of RTT. Planar scintigraphy can provide the information of iodine uptake. Tsai CJ [16] reported that ${ }^{131} \mathrm{I}-\mathrm{WBS}$ detected 206 lesions of RTT, while ${ }^{99 \mathrm{~m}} \mathrm{TcO}_{4}{ }^{-}$planar scintigraphy revealed only 122 (59\%) lesions. ${ }^{131}$ I is characterized by high sensitivity, which is conventionally performed as 

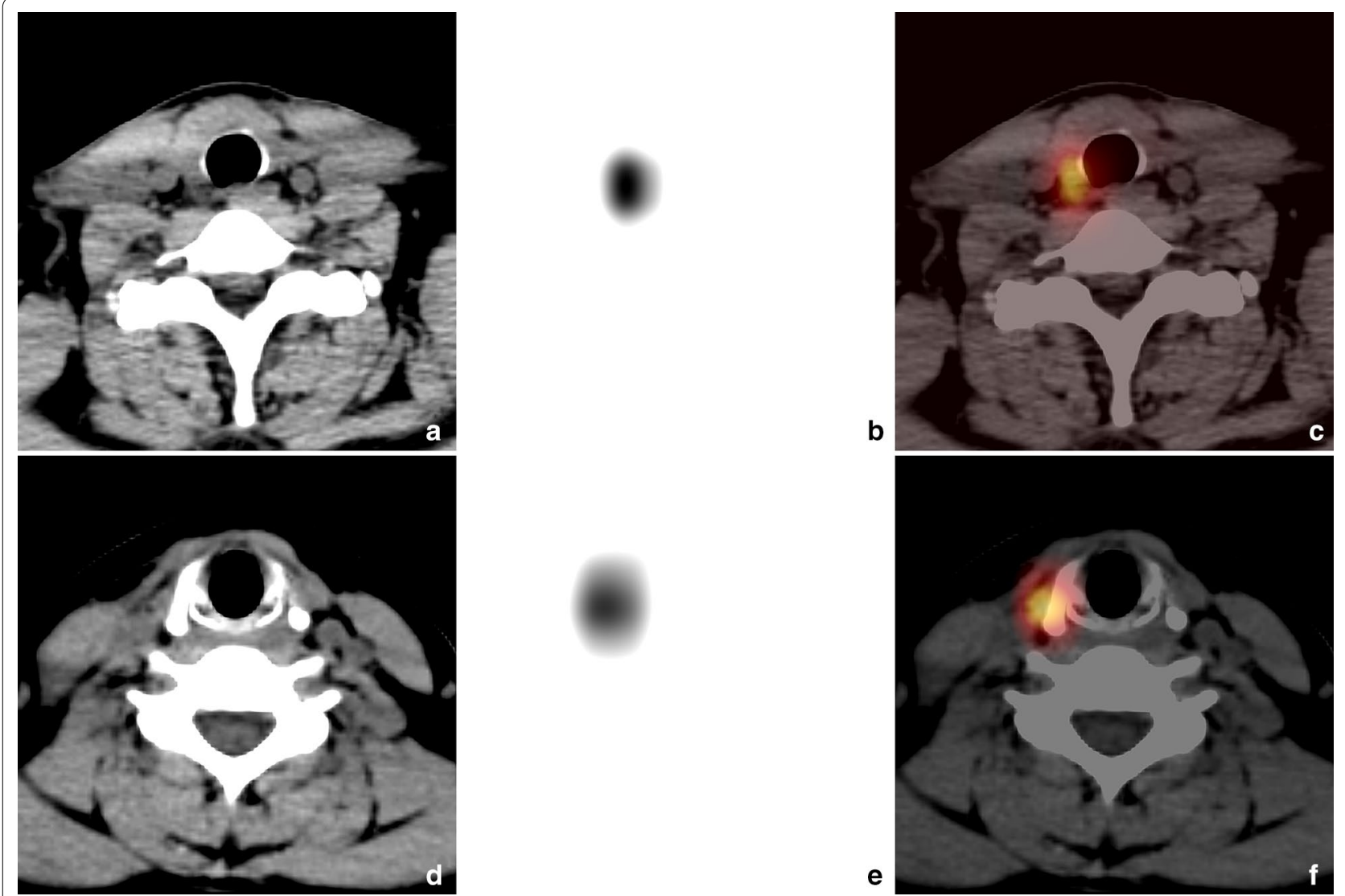

Fig. 3 RTT lesions of type II (suspected positive CT findings). The images (a CT; b SPECT; $\mathbf{c}$ fusion) were obtained from a 38-year-old man with PTC, who underwent total thyroidectomy 3 months ago. SPECT/CT demonstrated a RTT lesion with high-uptake and suspected thickened soft tissue, adjacent to the right side of tracheal cartilage (region I). The images (d CT; e SPECT; f fusion) were obtained from a 31-year-old woman with PTC, who underwent total thyroidectomy 2 months ago. SPECT/CT revealed a RTT lesion with high-uptake and blurry patchy shadow, adjacent to the thyroid right lamina (region IV)

Table 2 Location and SPECT/CT features of RTT

\begin{tabular}{|c|c|c|c|c|c|c|c|}
\hline \multirow[t]{2}{*}{ Region } & \multirow[t]{2}{*}{ Number } & \multicolumn{3}{|c|}{ SPECT uptake level } & \multicolumn{3}{|c|}{ CT finding } \\
\hline & & Low-uptake & Moderate-uptake & High-uptake & Type I & Type II & Type III \\
\hline । & 37 & 5 & 8 & 24 & 4 & 12 & 21 \\
\hline$\|$ & 11 & 2 & 3 & 6 & 0 & 4 & 7 \\
\hline III & 10 & 1 & 5 & 4 & 1 & 2 & 7 \\
\hline IV & 17 & 2 & 5 & 10 & 5 & 3 & 9 \\
\hline V & 3 & 0 & 2 & 1 & 0 & 0 & 3 \\
\hline VI & 2 & 0 & 1 & 1 & 0 & 0 & 2 \\
\hline Total & 80 & 10 & 24 & 46 & 10 & 21 & 49 \\
\hline
\end{tabular}

WBS in anterior and posterior views for the evaluation of RTT and metastatic lesions. ${ }^{131} \mathrm{I}$-SPECT/CT provides the precise localization of uptake foci, which helps to differentiate RTT in common locations from metastatic lymph nodes, as well as the identification of ectopic thyroid tissue, such as thyroglossal canal, root of tongue, etc. Cheng X [17] conducted a retrospective analysis of 73 DTC patients, and found that ${ }^{131}$ I-WBS made definite diagnosis only in $44(60.3 \%)$ patients, while ${ }^{131} \mathrm{I}$-SPECT/ CT made it in 71(97.3\%) patients. Spanu A [18] reported that 116 uptake foci from 52 patients were revealed by ${ }^{131}$ I-WBS, while a total of 158 foci from 59 patients were 
Table 3 The correlation between various clinical data and groups

\begin{tabular}{|c|c|c|c|c|c|}
\hline \multirow[t]{2}{*}{ Data } & \multicolumn{2}{|l|}{ CT findings } & \multirow[t]{2}{*}{ Total } & \multirow[t]{2}{*}{$x^{2}$} & \multirow[t]{2}{*}{$P$} \\
\hline & Positive group & Negative group & & & \\
\hline \multicolumn{6}{|l|}{ Age } \\
\hline$\geq 55$ & 2 & 4 & 6 & 0.072 & 0.789 \\
\hline$<55$ & 16 & 25 & 41 & & \\
\hline \multicolumn{6}{|l|}{ Gender } \\
\hline Male & 9 & 16 & 25 & 0.119 & 0.730 \\
\hline Female & 9 & 13 & 22 & & \\
\hline \multicolumn{6}{|l|}{ Pathology } \\
\hline PTC & 18 & 27 & 45 & 1.297 & 0.255 \\
\hline FTC & 0 & 2 & 2 & & \\
\hline \multicolumn{6}{|c|}{ Operation mode } \\
\hline Mode 1-2 & 3 & 3 & 6 & 0.399 & 0.528 \\
\hline Mode 3 & 15 & 26 & 41 & & \\
\hline \multicolumn{6}{|c|}{ Primary thyroid tumor } \\
\hline Unilateral & 15 & 8 & 23 & 4.778 & 0.029 \\
\hline Bilateral & 8 & 16 & 24 & & \\
\hline \multicolumn{6}{|l|}{ T stage } \\
\hline $\mathrm{T} 1$ & 13 & 8 & 21 & 26.413 & 0.000 \\
\hline $\mathrm{T} 2$ & 10 & 7 & 17 & & \\
\hline T3-4 & 2 & 7 & 9 & & \\
\hline \multicolumn{6}{|l|}{ N stage } \\
\hline NO & $2-1$ & 0 & 1 & 1.646 & 0.199 \\
\hline N1 & $21-17$ & 29 & 46 & & \\
\hline \multicolumn{6}{|l|}{ M stage } \\
\hline Mo & 18 & 27 & 45 & 1.297 & 0.255 \\
\hline M1 & 0 & 2 & 2 & & \\
\hline
\end{tabular}

detected by ${ }^{131} \mathrm{I}$-SPECT/CT. Therefore, compared with ${ }^{131}$ I-WBS, ${ }^{131}$ I-SPECT/CT can significantly improve the diagnostic accuracy and detection rate of lesions $[18,19]$. Although ${ }^{131}$ I SPECT/CT has been widely used for the evaluationg of RTT after thyroidectomy, while the distribution characteristics of RTT have not been systematically summarized. Avoiding the occurrence of RTT mainly depends on the careful clearance of surgeons, while the investigation on the distribution characteristics and risk factors of RTT will undoubtedly provide some guidance for improving the quality of surgery. In view of the lack of relevant literature, the present study originally divided the locations of RTT into six regions (I-VI). A total of 80 lesions of RTT were revealed by neck SPECT/ CT, most of which were located in region I (46.3\%, 37/80), followed by region IV $(21.3 \%, 17 / 80)$. This results suggested that RTT lesions are more associated with trachea cartilage and lamina of thyroid cartilage. Its detail mechanism is not clear and need to be further explored. It may be related to the anatomical characteristics of thyroid. The slender tip of thyroid lateral lobe adjacent the lamina of thyroid cartilage makes it challenging for the surgeon to completely remove all thyroid tissue in that location. The long-term compression of tumor makes it necessary to reserve some soft tissues around the tracheal cartilage to avoid its collapse due to the loss of support. The intimae relationship between the RLN and the inferior thyroid artery (ITA) or Zuckerkandl tubercle (ZT) makes some thyroid tissue may be retained [20-24]. In addition, other generally accepted views on RTT generation include: (1) thyroid tissue left attached to a parathyroid gland in order to preserve its vascularity [25]; (2) thyroid tissue at the superior portion of the pyramidal lobe of the thyroid; (3) the defect of upper respiratory function and structure should be minimized in DTC resection.

This study demonstrated that most RTT $(87.5 \%, 70 / 80$, type II-III) were negative or suspected positive on CT, which could be interpreted as intraoperative invisible lesions and difficult to be detected and removed by surgeons. However, the remaining $(12.5 \%, 10 / 80)$ RTT were revealed definite abnormalities on $\mathrm{CT}$, most $(50.0 \%)$ of them located in regions IV. These RTT lesions should be visible and detectable by naked eye during operation, which can be removed surgically. This means that the 
incidence of RTT may be reduced by about $10 \%$, as long as the surgeons strengthen the careful removal of the correct regions, especially the region adjacent to lamina of thyroid cartilage. Moreover, this study also displayed that patients with DTC involving bilateral thyroid tissue or in T3-4 stage were more likely to have RTT with CT abnormalities after surgery. It suggests that surgeons should pay more attention to the careful removal when the primary thyroid tumor involving bilateral or T4 stage. Therefore, this study maybe provide a new idea and clear guidance for surgeons for the careful surgical removal.

\section{Conclusions}

In summary, RTT has certain characteristic distribution and appearances on SPECT/CT. The definite positive CT findings can be noted in $12.50 \%$ of RTT, $50.0 \%$ of which were located adjacent to lamina of thyroid cartilage. It suggests that surgeons should strengthen the careful removal of thyroid tissue in this region, especially primary thyroid tumor involving bilateral and T4 stage. This study can provide a certain value for the improvement of thyroidectomy quality in DTC patients.

\section{Acknowledgements}

This work was supported by "Guangzhou Key Medical Discipline Construction Project Fund".

\section{Authors' contributions}

FW: collected the data, analyzed the data and reviewed the final manuscript. $\mathrm{HN}$ : collected the data, wrote the paper and reviewed the final manuscript. WL: conceived and designed the study, analyzed the data, wrote the paper and reviewed the final manuscript. RZ: conceived and designed the study and reviewed the final manuscript. WL: collected the data; analyzed the data and reviewed the final manuscript. All authors read and approved the final manuscript.

\section{Availability of data and materials}

Data and materials during the current study are available from the corresponding author upon reasonable request.

\section{Declarations}

\section{Ethics approval and consent to participate}

The ethics of this study were reviewed and approved by the Institutional Review board of Affiliated Cancer Hospital \& Institute of Guangzhou Medical University. All patients provided written informed consent. This was a retrospective study, which used clinical data acquired from patients of DTC.

\section{Consent for publication}

Not applicable.

\section{Competing interests}

The authors declare that they have no competing interests.

\section{Author details}

'Department of Nuclear Medicine, Affiliated Cancer Hospital \& Institute of Guangzhou Medical University, Guangzhou 510095, Guangdong Province, China. ${ }^{2}$ Department of Health Care, Affiliated Cancer Hospital \& Institute of Guangzhou Medical University, Guangzhou 510095, Guangdong Province, China.

Received: 1 March 2021 Accepted: 27 April 2021

Published online: 08 May 2021

\section{References}

1. Liu C, Zhao Q, Li Z, Huang T, et al. Mixed subtype thyroid cancer: a surveillance, epidemiology, and end results database analysis. Oncotarget. 2017;8:86556-65.

2. Wu YJ. Thyroid cancer has become a serious public health problem. J Chin Endocrinol Metab. 2015;31:1-3.

3. Hedman C, Djärv T, Strang P, Lundgren Cl. Effect of thyroid-related symptoms on long-terra quality of life in patients with differentiated thyroid carcinoma: a population-based study in Sweden. Thyroid. 2017:27:1034-42.

4. Haugen BR, Alexander EK, Bible KC, Wartofsky L, et al. 2015 American thyroid association management guidelines for adult patients with thyroid nodules and differentiated thyroid vancer: The American thyroid association guidelines task Force on thyroid nodules and differentiated thyroid cancer. Thyroid. 2016;26:1-133.

5. Uchida H, Imai T, Kikumori T, Kiuchi T, et al. Long-term results of surgery for papillary thyroid carcinoma with local recurrence. Surg Today. 2013:43:848-53.

6. Kayalar AE, Eyupoglu EE, Akyildiz S, Bakir A, et al. Thyroid carcinoma presenting as a dural and calvarial metastasis mimicking a lipoma with difficult diagnosis of the primary lesion. J Craniofac Surg. 2018;29:e684-6.

7. Hassan FU, Mohan HK. Clinical utility of SPECT/CT imaging post-radioiodine therapy: Does it enhance patient management in thyroid cancer? Eur Thyroid J. 2015;4:239.

8. Zilioli V, Peli A, Panarotto MB, Giubbini R, et al. Differentiated thyroid carcinoma: incremental diagnostic value of ${ }^{131}$ I SPECT/CT over planar whole body scan after radioiodine therapy. Endocrine. 2017;56:551-9.

9. SW LEE. SPECT/CT in the treatment of differentiated thyroid cancer. Nuel Med Mol Imaging. 2017;51:297-303.

10. Avram AM. Radioiodine scintigraphy with SPECT/CT: an important diagnostic tool for thyroid cancer staging and risk stratification. J Nucl Med Technol. 2014;42(3):170-80.

11. Ciappuccini R, Heutte N, Lasne-Cardon A, Bardet S, et al. Tumor burden of persistent disease in patients with differentiated thyroid cancer: correlation with postoperative risk-stratification and impact on outcome. BMC Cancer. 2020:20:765.

12. Jeong SY, Lee SW, Kim HW, Lee J, et al. Clinical applications of SPECT/CT after first I-131 ablation in patients with differentiated thyroid cancer. Clin Endocrinol. 2014;81:445-421.

13. Zhang $X Y$, Song HJ, Qiu ZL, Luo QY, et al. Pulmonary metastases in children and adolescents with papillary thyroid cancer in China: prognostic factors and outcomes from treatment with ${ }^{131}$. Endocrine. 2018:62:149-58.

14. Jung JS, Lee SM, Kim SJ, Han SW, et al. Prediction of the success of thyroid remnant ablation using preablative $99 \mathrm{mTc}$ pertechnetate scintigraphy and postablative dual 1311 scintigraphy. Nucl Med Commun. 2015;36:38-44.

15. Lee SJ, Chong S, Kang KH, Kim SJ, et al. Semiautomated thyroid volumetry using 3D CT: prospective comparison with measurements obtained 
using 2D ultrasound, 2D CT, and water displacement method of specimen. AJR Am J Roentgenol. 2014;203:525-32.

16. Tsai CJ, Cheng CY, Shen HY, Huang WS, et al. TC-99m imaging in thyroidectomized differentiated thyroid cancer patients immediately before I-131 treatment. Nucl Med Commun. 2016;37:182-7.

17. Cheng X, Li YJ, Xu ZQ, Yuan XJ, et al. Clinical significance of SPECT/ CT fusion imaging for diagnosis and staging in patients with DTC. Lab Immun Clin Med. 2019;26(44-47):63.

18. Spanu A, Solinas ME, Chessa F, Madeddu G, et al. ${ }^{131}$ I SPECT/CT in the follow-up of differentiated thyroid carcinoma: incremental value versus planar imaging. J Nucl Med. 2009:50:184-90.

19. Schmidt D, Szikszai A, Linke R, Kuwert T, et al. Impact of ${ }^{131}$ I SPECT/Spiral CT on nodal staging of differentiated thyroid carcinoma at the first radioablation. J Nucl Med. 2009;50:18-23.

20. Barczyński M, Konturek A, Stopa M, Nowak W, et al. Clinical value of intraoperative neuromonitoring of the recurrent laryngeal nerves in improving outcomes of surgery for well-differentiated thyroid cancer. Pol Przegl Chir. 2011;83:196-203.

21. Noussios G, Chatzis I, Konstantinidis S, Katsourakis A, et al. The anatomical relationship of inferior thyroid artery and recurrent laryngeal nerve: a review of the literature and its clinical importance. J Clin Med Res. 2020;12:640-6.
22. Cho I, Jo MG, Choi SW, Cha W, et al. Some posterior branches of extralaryngeal recurrent laryngeal nerves have motor fibers. Laryngoscope. 2017;127:2678-85.

23. Won HJ, Won HS, Kwak DS, Kim IB, et al. Zuckerkandl tubercle of the thyroid gland: correlations between findings of anatomic dissections and CT imaging. AJNR Am J Neuroradiol. 2017;38:1416-20.

24. Irkorucu O. Zuckerkandl tubercle in thyroid surgery: Is it a reality or a myth? Ann Med Surg (Lond). 2016;7:92-6.

25. Dos Reis LL, Mehra S, Scherl S, Urken ML, et al. The differential diagnosis of central compartment radioactive iodine uptake after thyroidectomy: anatomic and surgical considerations. Endoc Pract. 2014;20:832-8.

\section{Publisher's Note}

Springer Nature remains neutral with regard to jurisdictional claims in published maps and institutional affiliations.
Ready to submit your research? Choose BMC and benefit from:

- fast, convenient online submission

- thorough peer review by experienced researchers in your field

- rapid publication on acceptance

- support for research data, including large and complex data types

- gold Open Access which fosters wider collaboration and increased citations

- maximum visibility for your research: over $100 \mathrm{M}$ website views per year

At BMC, research is always in progress.

Learn more biomedcentral.com/submissions 